\title{
Change of the Materiality with the Changing Law of Temporality
}

\author{
Xucheng Chen ${ }^{1, *}$
}

${ }^{1}$ the Ohio State University, 186 University Hall 230 North Oval Mall, College of Arts and Science, Columbus, Ohio, U.S.A, 43210

*Corresponding author. Email:963349408@qq.com

\begin{abstract}
The subsisting of immobile bromide film signs has a lot to do with one of the definitions of art that stressed on truth. However, unlike a scientific fact that is universal everywhere, the truth emerged through sensations and awe are often subjective perspective. Thus, the relationship between the creators and spectators is crucial that decides the purpose of the art. Based on the hierarchies of the medieval time and egalitarianism of the post-modern time, this paper will talk about how the invention of photography and film changes the entrenched power relations of the past and thus determines the change of the functions of the art. Unlike paintings, which are constructed totally at the will of creators and artists, photography allows a certain degree of uncontrollability and freedom conferred by the laws of the nature where everything is abided by. This change of the origin of the subject matter changed the power relations today and changed our society from dictatorship to democratic, from exterior to interior, from passive acceptance to skepticism. This passage is meant to analyze the great transition of purpose of art and to explore the influences of the art that can have on today's society.
\end{abstract}

Keywords: Philosophy, temporal arts, hierarchy, aesthetic, spectatorship

\section{INTRODUCTION}

Almost 50 years ago, Susan Sontag in her book On Photography had said that "I have already seen anything", which is also true nowadays even though 50 years has passed. However, why is that? What kind of influences can such a staleness bring to us? Normally, we call such staleness as "aesthetic". Kant discussed aesthetic comprehensively in his book The Critique of Judgment, but I am not going to summarize what he said in the book. Instead, this passage is meant to analyze some instinctive features of the film, that we have taken for granted for a long time, that breaks this deadlock. This study will initially analyze the relation between power structure and definition of art. Then it will explain how the relation is changed with the advent of the camera. At last, it will discuss the further influences and novelties emerged through cinema.

\section{DEFINITION OF SPATIAL ART ACCORDING TO MATERIALITY AND ITS FORMATION}

On the topic of imitation and representation, the imitation theory attaches a great importance to how the ideologies, or the emblem of the real life is being presented in the artwork. Plato believes that art is mimetic by nature; eventually, every art piece is a reflection of the real life.

He believed that truth of this world is the definition of the art. However, such theory failed to explain the existence of the "preternatural", like God. Thus, the representation theory said that $\mathrm{x}$ represents $\mathrm{y}$ if only $\mathrm{x}$ intended to represent $\mathrm{y}$ and spectators can realize that $\mathrm{x}$ is intended to stand for $y$. Aristotle believes that art is, first, to look like or resemble, second, to stand in for something, and at last, to present a second, namely, to represent. Martin Heidegger believes the a priori of the art to be the "truth" which "can unconcealed itself through this process of bringing forth the earth and bring back the world [1]" No matter Greek philosophy 
or analytical philosophy all attaches greater importance to truth in how it was produced. Therefore, while making art, what's important for artist is to manifest the beliefs, ideologies, and subjectivities through observable and solid materials like canvas and marbles so the spectators and audiences can be aware of the concept of the work by gathering information through observable techniques and materials. It is through the bring forth of the earth and bring back of the world that truth can unconceal itself. In the Origin Work of Art, Heidegger believes that Earth mainly represents the materiality of artwork and the world mainly represents the ideology. In social science, Materiality is the notion that the physical property of a cultural artifact has consequences or how the object is used [2]. For example, in order to explain these consequences and influences, Heidegger in his article, the origin of the work of art, explained why Van Gogh's painting A Pair of Shoes can be considered as a marvelous work of art. Because the ideology and inspiration behind this painting is peasant, and what's been applied on the canvas, like the color, the dirt, and wrinkles on the shoes, and the ambiguous yet blank ambience all agree with the humble and parsimonious qualities of the career of the owner, peasant, of this pair of shoes, thus, this painting is considered as a masterpiece. This conformity between the materials and ideas is generally what Heidegger believes to be the truth of the artworks. However, this connection between ideas and materials is directly derived from the symbolism and aesthetic, which makes the truth taught and derivative and thus a posteriori instead of "a priori" because such truth is derived from experience. Thus, the so-called eminence or beauty of this painting, A Pair of Shoes, is not a priori but posteriori.

Such posteriori truth rampantly existed in the art world not only of the past but also of the current time, and this heavy inclination towards the building of truth based on experience has a lot to do with the relationship between hierarchies and aesthetic. Beauty is what aesthetic blatantly means. According to Kant, to call something beautiful not only requires pleasure and emotional sensations received from the thing, but also requires reflexive contemplation. Kant said, "If he proclaims something to be beautiful, then he requires the same liking from others; he then judges not just for himself but for everyone and speak of beauty as if it were a property of things [4]." Heidegger also agreed that the synonymous of aesthetics is a "common sense [5]" that everybody consents with. For example, under the western aesthetic, black and dark tonalities represent something sinister while white and bright colors represent something sane and holy. Like the white is often massively applied in paintings in depiction of Heaven, while black becomes the spokesmen of the hell. However, the color black and white don't instinctively equip with certain properties that can trigger the sensations of neither sinister/evil nor holy/good. Thus, this common judgement formed based on simply objective paint, a patch of color, is beyond the simple truth but stands for the process of normalization.

As Foucault said in the Discipline and Punish at chapter of the Means of Correct Trainings, normalizing judgements involved a series of rules that are held and supported to keep the society in the most ideal form and then crediting those who conform with the rules and punishing those who should infringe those rules. This gratification-punishment system associates the deviated behaviors as evil and those conforming and docile ones as good. Then, it assigns behaviors into a rank and hierarchies from the most credited to the most punished. Through this hierarch, a common judgement is built, and a taught truth is conveyed. The modality of such a truth is most obvious by the religious themed artworks produced in that 15th century, and normally to accentuate the ruling position of the church for the purpose of maintaining the social order or even its supreme power and privileges. The church will commission the artist to meet their ends for indoctrinating religious creed, for inciting awe and admiration deep within the mind of the followers and potential supporter, and at last to create a connection between the church and Catholics.

Some of the deeds of the church really help a chaotic society, which just went through a turmoil, black death, to rebuild. For example, a very common theme of crucifixion is frequently depicted in renaissance paintings to promote this doctrine of loyalty to encourage a high value of morale to stabilize the social order. However, we cannot deny that, besides playing an important role in managing a society, the church and the taught truth also encouraged a privilege. Church tries very hard to ensure their truth can never be overturned because, according to Kant, everybody has their own taste, so the idea of aesthetic is actually very flimsy and need to be strengthened from time to time. Thus, they do it in two steps through commission and connection. They first build a connection for people to buy their story in the first place, like the Story of Moses leading people across the red sea. Such a story is highly skeptical in today's society but at that time, people can 
be credulous for the whole society is eclipsed by a huge fear of uncertainty created by the black death. Nobody knows what exactly it is that took their lives. People at that time lived a very frightened and restive life, and worst of all, no one to count on. Thus, such a divine, powerful, and yet so uncanny a story can easily make people hold on to subsist. This dependence makes the church the leader of people's hope. Even though church did bring back the stability and safety to the society, commission for the great artist serves more like insurance to ensure that people will continue to believe in the church instead of as a benefit for the civilians.

From connection to the commission, from believing to a total prostration, they did it through normalization by creating a strict logic between things to crowd out all kinds of deviation. This modality can also be evinced through a university discussion on Theology and Falsification where Basil Mitchel proposed a theory on the "trial of faith" to illustrate why people can still believe in religion when there are hardships. Since pain counts against the assertion that God loves us, and thus we have the concept of evil. However, the theologian is well aware of this problem of evil that counts against the doctrine, and they acknowledge the existence of evil, even so, what they have to do is to ensure that this evil will not crowd out the faith and religious decisively. Thus, to explain evil, they created sins and advised people to punish themselves for washing away their sins. However, to convince people that they are sinful is not the primary reason why people refuse to abandon their faith, but logic, Foucault said:

The Christian, once he has committed himself, is precluded by his faith from taking up the first attitude (as a provisional hypothesis to be discarded if experience tells against them): 'Thou shalt not tempt the Lord thy God.' He is in constant danger, as Flew has observed, of slipping into the third (as vacuous formulae - expressing, perhaps, a desire for assurance, to which experience makes no difference and which makes no difference to live). But he need not; and, if he does, it is a failure in faith as well as in logic. (48-49) [5]

Thus, the strict logic promises the foundation of the truth and intentionally crowds out the possibilities of what personal taste can bring to the interpretation of a representation. They eliminate other interpretation through normalization to secure the churches' exclusive right to give meanings because the crumbling of the logic will directly bring forth the crumbling of the faith in church and thus the loss of the control of the public.
This intention to hold its premium position can also be proved through most of the catholic paintings and sculptures like Pieta and Madonna and Child, because they will always be put high on the plateau in the church to create a difference of height between the work and spectators to create a difference of position for people to admire. Also, a lot of other techniques like the gossamer veil on the face of Madonna also strengthened a sense of ethereal that differentiates her from the mortal life and commonality. At last, the depiction of the significant scenes from the bible like Crossing the Red Sea gives a lot of undereducated civilians a hope that the church has the magic power to save them from the misery when most of the people just escaped from the horrible black death. Gradually, religious themed artworks and especially paintings become the most praised genre and subject matter to choose from while creating for not only such theme is highly popular among the mass public but also encouraged by the church with certain remuneration. This trend can also be proved through the hierarchal genres in the modern era of art. This hierarchy ranked from the most prestigious to the most despised are: History paintings (historically important, religious, mythological, or allegorical), portrait paintings, genre paintings, Landscape, Animal Paintings, and, at last, still life [6]. History painting including themes involving religious theme, mostly comprised of bible stories, allegorical stories of Greece, are the utmost being appreciated. Through associating the transcending ideas with the actual materiality of a physical property, artworks indeed render some truth, but such truth is posteriori and always with the purpose of controlling the mass public for the definition of such truth is always determined either by the church or by the artist in this case. Thus, art is no longer a representation of the truth but more like a leader of the society. Thus, such truth is no longer "priori" or ultimate truth for white is not "white" anymore but an emblem of sacred and thus such truth becomes derivative and thus posteriori. Also, with church and artist being put at such a high rank, such truth serves more as a controlling apparatus.

No matter the definition of art as the representation of the idea or like Heidegger said the "bring forth of the art, and the bring back of the world", they all try to convey the truth through the materiality of the artworks. However, with the promotion of strict logic, art is no longer to find truth or to represent the truth through the artwork, since the truth has become common sense and aesthetic, whose definition of the good work has become expected and solidified among audiences, now 
can simply be gratified through the piling up of certain qualities, symbols and techniques. Like what Susan Sontag said in her book, On Photography, that "I have seen everything" [7], because nothing new had appeared since a very long time ago. The recycling and rehash of aesthetics crowd out the different interpretations of the connection between the same two or several objects and episodes.

\section{TRADITIONAL MATERIALITY NOT AS THE DEFINING ELEMENT OF CURRENT ART}

However, this long ruling of hierarchal of genres are successfully challenged and replaced by

impressionism with a focus on everyday objects and banalities because of the introduction of the Japanese woodblock painting. Manet's Olympia is a very good example of this that totally overturns the traditions supported by the traditional art world inherited from the aesthetic of the church. The reasons why Manet can break free from this loop created by church, which totally denies self-conflicting, is because of the beginning of the globalism that helps to import a lot of eastern artifacts into France. Thus, this new culture enables Manet to question the truth of the church and tradition and start to adopt a different system of aesthetic, like a shallow depth of space inherited from the traditions of Chinese water ink paintings versus the traditional 3-dimentional way of depicting space; The depiction of the leisure time versus the historically or religiously important stories. However, what's more important about the impressionism is to adapt a different aesthetic or standard to challenge the traditional art industry of the west. For example, besides using a different system of aesthetic as the foundation of the painting, the subject matter of the Olympia by Manet is also daring, focal point of the whole painting, suggested by Olympia's hand covering her vagina and that eastern screen in the back, is actually off from the center; Not mention the model, Olympia, whose occupation is a prostitute; plus, her stare is so direct and unflinching looking right into the audiences who are completely comprised of men. This turn of focus initiated by Manet opens a great art movement: impressionism which aims to challenge the whole morals and values of society with the help of the change of the aesthetic at the early stage of impressionism's development, and therefore helps the post-modernism to develop more maturely, and then directly leads to the transition from modern time to post-modern time.
However, since paintings and sculptures still depend on certain techniques working on materials to render the truth, such truth can be inevitably quickly transferred into a different aesthetic and cause the same problem as those religious paintings do. Thus, in order to deter people to keep believing in the standards of the Académie des Beaux-Arts or to overthrow the whole power relations, impressionistic painters started to adopt everyday banalities. It is because of this shift of focus from the significant incidents to everyday banalities that justify the acclaimed position of impressionism and opened up every famous art movement followed up. Because what is being presented on the canvass is what we see every day, and this plain norm confounds and even irritate some art critics, like those we talked about before, for what is being presented on the cavass is literally a ripped off of real life, and thus, what's more is there to see? There used to be an impressionistic painter named Frederic Bazille, who finished a work called the Family Gathering (1867) which portrays a group of people standing and sitting under a big tree. However, this piece was rejected by the Académie des Beaux-Arts, the authority of the art world at Paris, for being too "photographic". Which it's true, this one is pretty "documenting" with people sitting or standing under the tree, staring back vacantly at the audiences, and with trees and skies comprising most part of the background. What Académie des Beaux-Arts mean is this piece especially the figures within the paintings are just like a bunch of deadly still lives lack any room for people to imagine and interpret due to a lack of a historical or cultural context. Without the backdrop of the story, connections and doctrines, what's left are simply subjects and objects themselves and thus meaningless. Mary Ann Donne also said: "Description is a capitulation to the cast and uncontrollable, and ultimately meaningless, realm of the contingent" [8]. Thus, this broken of modality directly brings hesitation.

\section{HOW TEMPORALITY CHANGED THE DEFINITION OF MATERIALITY}

However, such a rapture of logic can only bring hesitation but can barely reject it decisively due to its manipulatable materiality which naturally strengthens the power of the creator. The rupture of the logic of the traditional art directly builds an impressionistic logic, with a focus on everyday banalities, whose influences and power had lasted from the 1860s until today. Thus, impressionism in today's perspective, is not that postmodernistic. However, "photography", as we talked about before, is viewed as a "visual" art form too literal 
without any creative power. Literal" here means that, unlike paintings which acquire materiality that can be changed through the different use of color, techniques and compositions, early photography is solid and unchangeable. It is just because of this function that can capture the images without any alterations or distortion of what is being presented on the negative, photography-based art forms and film naturally have this ability to document events objectively and thus like Cavell said:" moving image of skepticism." [9]

However, with the development of the technology, the alteration technology changed from the simplest superimposition to current sophisticated CGI and PS, and the warping of the content is not that difficult. Thus, many people claim that the objective documentation power of film is false and subjective. However, we must understand, plus the documentation instinctively inherited from the camera, one thing that differentiates the art of photography from the art of film is the continuity and the involvement of the time. Even in some very subjective rendered films like the Wonder Ring by Stan Brakhage, we can still get an indifferent visual sense of what is like in New York City during the 60 s, like what were people wearing, what did the subway station look like, and how many skyscrapers had already erected back then, we can all find our answers in this one short 3-minute piece. In the Wonder Ring, Cameras bring all these objects before people's eyes according to the rules of how landscapes and buildings are being arranged in the city with alignment of the train traversing through it. The modalities of the objects that appeared in the film are thus no longer at the will of the camera man and the artist but more at the will of the arrangement of the city and the rules of the outer world and nature. Thus, in the film, artist's position as a leader and people who gives definition to tout their logic is totally smashed with the set rules this world operated upon on us. And thus shifted the mere pleasure and awe begotten from the deep within of the spectators to a passive acceptance and rumination of current time. This continuity of time and the involvement of the logic beyond creators themselves transfer cinema from spatial art to temporal arts.

It is because of the involvement of the time and the rules of the outer world that decisively rejected the definition of truth from the spatial art like painting, sculpture and even photography as posteriori. Because such art forms depend on art creators' projection and reflection of this world to synthesize, yet film flows with the time, and imitates what is happening around and becomes a priori. But it doesn't mean every film is a priori. Some film attaches a great importance on certain moments of the time like the climax or the denouement. Thus, even though the film continues with the moving of the time, but the definition of the time here is the building of the connections between incidents happened at various time to ensure the continuity of the logic that elicit the end. Thus, they believe the accuracy and the reliability of the scene are crucial for the successful building of the logic between the two episodes. However, as a temporal art, film attaches great importance to the continuity and moving of the time itself, meaning the simple documentation of the images or, according to Deleuze, the pure optical signs and sound signs, in synchronization with the moving of the time. The recording of the episodes is simply presenting what's before the camera with a the logic rooted in the outer world. The change of focus from creating logic to accepting inveterate logic of the outer environment shifts the creative power and the materiality of the film away from the content of the film. Thus, special effect and PS cannot change the reliability of the temoral film. However, in spatio film art, through close connections of the editing, the plot, the frames, and the shots, just like the continuity editing and linear perspective, Hollywood films combines more-or-less related shots, or different components cut from a single shot, into a sequence to direct the viewer's attention to a pre-existing consistency of story across both time and physical location. To explain the theme of the film, usually the goodness that is upheld by the society, each shot is serving like an explanatory factor. Also, part of the purpose of editing is to shorten the unnecessary time between critical incidents to ensure the cohesiveness of the plot and to drive away from the boredom. However, who should define what is necessary and what is not? Simply put, the film thus becomes a tool serving up for the explaining of an idea with a preconceived hierarchal from good to bad which had already defined what is necessary and what is not. Such film like those traditional art is meant to indoctrinate the director's ideas into the audiences and through some cliché to create a familiarized sensations out of the audiences so audiences can keep going to the cinema to spend money.

\section{CONCLUSION}

Thus, it proves again that what differentiates films from other art forms are not actually the solid materiality that so called spatial art relies on like painting, sculpture or photography. Temporal art differentiates from the spatio art mainly at the way 
different signs are connected, the modality. No matter the images being shot, or edited, they are the simplest way of constructing a film. However, they still have a difference. The materiality of the film is not actually existed in the cinema because physical properties like film and pixels, unlike traditional materialistic properties like brush strokes, that change the work itself so decisively. But this study believes there are still elements of the film that can have the same effects as those physical properties do, like editing. Thus, it can be argued that materiality is no longer simply the physical property used to form an art piece. It is just a property. More abstractly speaking, materiality is simply a basic quality that is being combined to illustrate an idea and stress the meanings of the meaninglessness. Like montage, for example, in Citizen Kane, the "rosebud" served as the ultimate clues or a time stamp through the whole film that explained the death of the Kane, not to mention that snowboard "rosebud" appears in film everywhere in deep focus, literal speech, and name. However, different from continuity editing, montage only stresses the meanings of the objects that are being presented but what exactly is the meaning of it is obscure. In other words, what montage or the creator did is like a catalyst trying to make a connection between the objective truth and subjective interpretations from the audiences. However, how such an interpretation is formed is totally up to the audiences. Thus, what really differentiates the spatio art and temporal art is the subjects who hold the right to define and make a connection. In the past, the subjective truth and objective truth is connected by the artists and taught to the mass public and gradually evolved becomes a discipline apparatus. However, today, there are artist choose to step down from this leading role who gives definition and simply serve to the needs of the audiences.

The reason why the position of the creator is diminished is because of the development of the psychology and a focus from physical properties to metaphysical properties. In Henri Bergson's matter and memory, he poses a question that is what we see is exactly the reality and imitation of this world or what our mind taught us to see? This is a question that can barely be solved for five of our organs, ears, nose, skin, eyes, and tongue only engage in stimulus collection and transduction sensations. Simply put, there is a difference between the objects being perceived and the images of the object that have been perceived. In this catenation, the world is perceived as indifferent, our eyes are simply an apparatus of collection information, however how we process this information in our mind is actually fickle and unpredictable. 2-D seeing of the aesthetic system of eastern art and the 3-D seeing of the aesthetic of western art is a very good example of how we process our date received by eyes from the outer world. In Stan Brakhage's Metaphors of Vision, he proposed that since our retina is flat and the image being projected on our retina should also be flat, but we still see images in a 3-dimentional way. The cause of it is that we are trying to understand the spatial relations of objects within the image. The 3-D way of seeing is also not inborn in western aesthetic. Before the medieval time, the woodblock painting still looks very flat. It is not after the Renaissance, when attaches a great importance on the logic and science, when people really started to apply the 3-D way of seeing. This stress on the logic is very easy to understand. By applying extreme close-ups shots in Wonder Ring, Stan Brakhage crowds out the diagonal lines and leaves massive room for vertical and horizontal lines to blur the depth of field and leave an illusion of flatness to the audiences to deprive the general meanings from the short. He also believes in closed eyes viewing like "seeing stars". The "stars" that people see actually is called visual noises and which appears, disappears, increases, decreases with the swings of the emotions. Also, the first report of the stars began with the introduction of the Television. Thus, many people purports that the stars are probably the "snow" and pixles on the TV. But such a theory has never been appropriately verified. However, this possibility complicates and aggravates the ground to answer Bergson's question even worse for not only will our mind change how we perceive the outer world, but the outer world will also change the way we perceive itself. Thus, what we actually see, or the data that we received from other worlds changes with a lot of elements and unpredictability.

With so much uncertainty going on, the watching of the film is not only a receiving of sensation or pleasure but the exploration and rumination of an unsolved dilemma between subjective truth and objective truth especially when today's films become more and more devoted to pure opsigns and sonsigns. Film itself becomes a cluster of meaningless signs of indifferent object subjugated to the rules of nature, and a bearer of spectator's that mirrors the mind and logic of audiences. Thus, the purpose of the art is no longer to led or as a discipline apparatus at the will of those in power. Instead, it becomes a tool that forces us to see ourselves. 


\section{REFERENCES}

[1] Heidegger, Martin. Being and time: the Origin Work of Art, translated by John Macquarrie and Edward Robinson, Harper \& Row, 1962: 265-268

[2] Lievrouw, Leah. "2: Materiality and Media In Communication and Technology Studies: An Unfinished Project". In Gillspie, Tarleton; Boczkowski, Pablo; Foot, Kirsten (eds.). Media Technologies: Essays on Communication, materiality and society. Cambridge, Massachusetts: The MIT Press. 2014: 21-51

[3] Kant, Immanuel. Critique of Judegement, translated by Werner S. Pluhar, Hackett Publishing Co., 1987: 55

[4] Heidegger, Martin. Being and time: the Origin Work of Art, translated by John Macquarrie and Edward Robinson, Harper \& Row, 1962: 270

[5] Flew, Anthony. "Reason and Responsibility: Readings in Some Basic Problems of Philosophy." Theology and Falsification, University College of North Straffordshire, 1950-1951, edited by Joel Feinberg, Dinckenson Publishing Company, inc., 1968: 6

[6] Belton, Dr. Robert J. "The element of Art". Art History: A Preliminary Handbook., 1996: 24

[7] Sontag, Susan. On Photography, Penguin Book, 1977: 50-75

[8] Donne, Mary Ann. "The Representability of time." The Emergence of Cinematic Time, Harvard University Press, 2002: 12

[9] Cavell, Stanly. The World Viewed: Reflections on the Ontology of Film, Havard University Press, 1971: 67 